\title{
GPS measurement at summit peaks of the Taisetsu mountains, Central Hokkaido, Japan
}

\author{
Takayuki Kaneso $^{1}$, Junji Koyama ${ }^{1}$, Takeo Moriya ${ }^{1}$, and Hiroaki Takahashi ${ }^{2}$ \\ ${ }^{1}$ Division of Earth and Planetary Sciences, Graduate School of Science, Hokkaido University, North 10 West 8, Kitaku, Sapporo 060-0810, Japan \\ ${ }^{2}$ Institute of Seismology and Volcanology, Graduate School of Science, Hokkaido University, North 10 West 8, Kitaku, Sapporo 060-0810, Japan
}

(Received December 31, 1999; Revised July 16, 2000; Accepted August 15, 2000)

\begin{abstract}
To investigate the precise crustal deformation in the Taisetsu mountains, Central Hokkaido, Japan, we have conducted GPS survey in 1998 and 1999. The coordinates at summit peaks of the mountain chain, horizontal displacements and strain are evaluated in this period. Major results are summarized as (1) horizontal displacements at the summit peaks are about $2 \mathrm{~cm}$ in the direction of north, (2) horizontal strain is estimated to be compressional in the NW-SE direction. Although the precision of the estimates awaits for the future survey, this results are consistent with the direction of the compressional axes of focal mechanism solutions of local earthquakes in the surrounding region and with the deformation vector by the triangulation in central Hokkaido.
\end{abstract}

\section{Introduction}

The Taisetsu mountains consists of many quaternary volcanic mountains over 2000 meters. The eruption of about 30,000 years ago formed Ohachi caldera and the last eruption is estimated about 500 to 600 years ago forming the explosion crater at the western flank of the mountains. The steaming activity of Mt. Asahidake is still active at present. The 1988 eruption of Mt. Tokachidake was phreatomagmatic with a pyroclastic flow of about $1 \mathrm{~km}$. In case of the 1926 eruption the massive debris/mud flow caused a large disaster. The volcanic activity of Mt. Tokachidake is in the alert watch level (Monthly Report on Earthquakes and Volcanoes in Japan, 2000).

The mountain chain is a part of the complicated structure in and near Japan with the interaction among Okhotsk, Pacific, and Eurasia plates (Fig. 1). In contrast to the volcanic activity, the seismic activity in this region is unexpectedly low (Fig. 2). This coincides with the small crustal deformation in the central part of Hokkaido (Tada and Kimura, 1987). The seismic activity and tectonics have to be investigated more in detail to understand the complex plate configuration in this region.

The triangulation survey has been conducted by Geographical Survey Institute of Japan (GSI). Crustal deformation by the survey is characterized by the northwestern movement in the eastern side and by the southeastern in the western side of the Taisetsu mountains (Tada and Kimura, 1987). This is generally consistent with the crustal deformation by the GPS measurement in the surrounding region of the mountain, which has been conducted by GSI in the last few year (GSI, 1999).

There are not enough GPS survey-data at the mountainous

Copy right (C) The Society of Geomagnetism and Earth, Planetary and Space Sciences (SGEPSS); The Seismological Society of Japan; The Volcanological Society of Japan; The Geodetic Society of Japan; The Japanese Society for Planetary Sciences. area to retrieve the present deformation. Our primary purpose is to know the precise/temporal crustal deformation in the mountain chain, which would not be made by analyzing the ten-year interval traditional survey and not by the GPS measurement in the surrounding region carried out by GSI.

\section{Observation and Data Analysis}

Table 1 summarizes the GPS survey in the Taisetsu mountains we have made in 1998 and 1999. We made the GPS survey three times. Each survey with three to five members took three days except for the last one in Table 1. Usually there is a bench mark used in the triangulation survey by GSI at the mountain peak. The one at Mt. Kurodake has been destroyed because of the collapse of the peak-cliff and some are heavily displaced because of the frost heaving. Otherwise the bench marks at the peaks are measured by GPS using tripods.

GPS data acquisition at each observation has been made for more than three hours at every thirty-second interval. We have analyzed the obtained data using Bernese GPS Software Version 4.0 (Rothacher and Mervert, 1996) with IGS precise ephemeris and International Earth Rotation Service (IERS) Bulletin-B earth rotation parameters.

Kamikawa GPS station of GSI is one of the closest to our surveyed area and its continuous data is available. The coordinate of Kamikawa in the IERS Terrestrial reference frame (ITRF) 96 is evaluated relative to Tsukuba (TSKB) IGS global tracking station. The coordinates at each summit peak are evaluated referring to the Kamikawa's. The advantage to analyze L1 and L2 band data is to evaluate the correction of the delay due to the ionosphere. Since the baseline lengths between Kamikawa and our GPS sites are about $10 \mathrm{~km}$, the delay on the measurements would be the same. Therefore, we have used only L1 data for the analysis. Since this excludes noisy L2 band data, the estimation error is usually reduced. Tropospheric delays are estimated at each station in every 


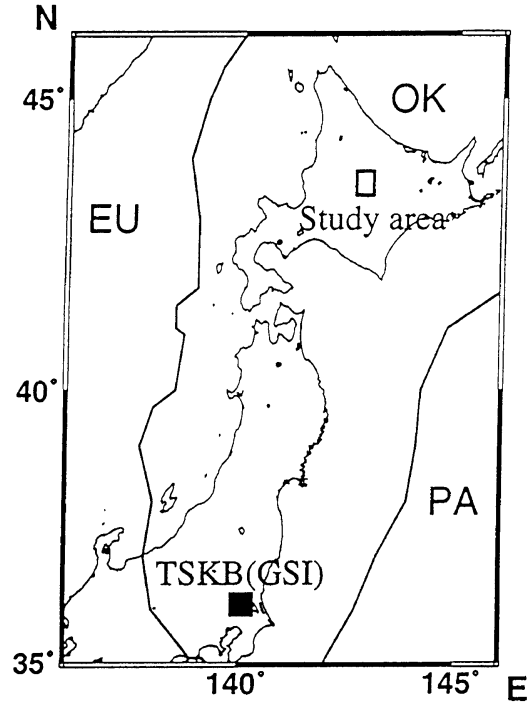

Fig. 1. Study area of the Taisetsu mountains is indicated by a rectangle and plate boundaries in and near Japan. OK, PA, and EU indicate the Okhotsk, the Pacific, and the Eurasia plate, respectively. TSKB with solid rectangle indicates Tsukuba IGS global tracking station.

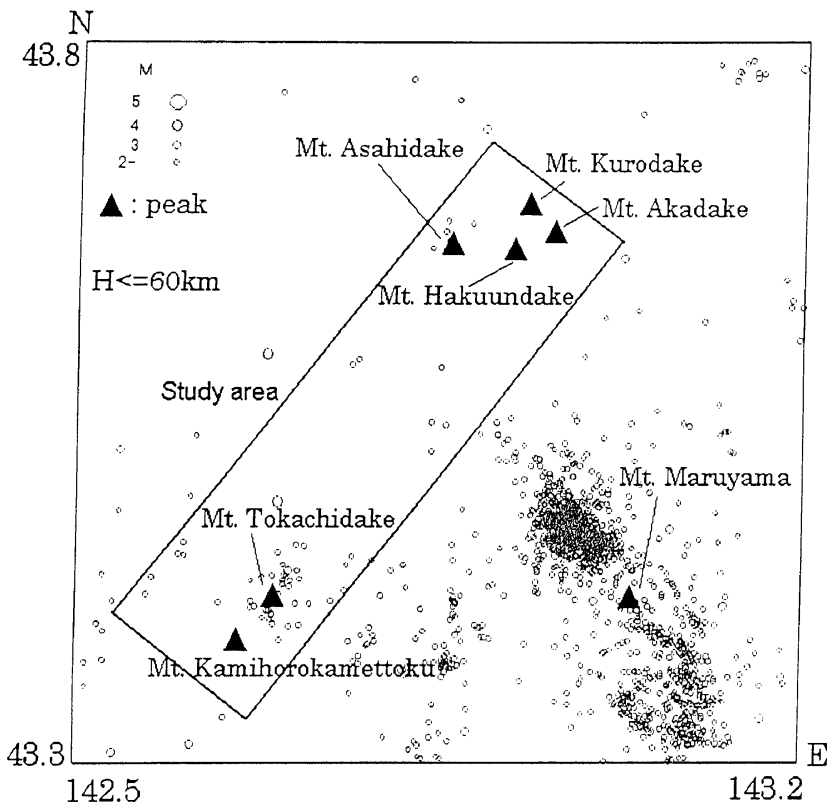

Fig. 2. Seismic activity in and near the Taisetsu mountains from July 1976 to September 1999 (Hokkaido University, 1999) and the GPS observation points at summit peaks are shown. Swarm activity is near Mt. Maruyama and the volcanic activity is there also.

three-hour.

There is an elevation difference more than $1000 \mathrm{~m}$ between Kamikawa station and summit peaks. We did not evaluate the atomospheric effect coming from this elevation change. Therefore, elevation coordinates of summit peaks are less reliable compared to their horizontal coordinates. Here we confine our interest only to horizontal displacements at summit peaks from 1998 and 1999 observations.

\section{Results and Discussion}

Figure 3 shows the horizontal displacements at the summit peaks of the mountain chain with respect to Kamikawa, and the horizontal strain evaluated. Horizontal displacements at Kurodake, Hakuundake, and Asahidake are as much as $2.6 \mathrm{~cm}\left(\mathrm{~N} 10^{\circ} \mathrm{E}\right), 2.5 \mathrm{~cm}\left(\mathrm{~N} 22^{\circ} \mathrm{W}\right)$, and $1.3 \mathrm{~cm}\left(\mathrm{~N} 21^{\circ} \mathrm{E}\right)$ in this period, respectively. Principal strains are $-5.46 \times 10^{-6}$ (compression directing $\mathrm{N} 56^{\circ} \mathrm{W}$ ) and $2.38 \times 10^{-6}$ (extension directing $\mathrm{N} 34^{\circ} \mathrm{E}$ ) in this area.

The amount of deformations seems to be too large. Since this result has been obtained from the measurement in a relatively-short time-duration of three hours and in one year interval, the precision of the measurement will be improved by the repeated survey in the future. Considering the magni-

Table 1.

\begin{tabular}{lcr}
\hline & 1998 (one party) & 1999 (two parties) \\
\hline Mt. Kurodake & July 28 (3 hours) & July 20 (3 hours) \\
Mt. Hakuundake & July 29 (6 hours) & July 21 (7 hours) \\
Mt. Asahidake & July 30 (3 hours) & July 21 (3 hours) \\
Mt. Akadake & - & July 21 (3 hours) \\
Mt. Kamihorokamettoku & - & September 19 (5 hours)
\end{tabular}

Receiver: TOPCON GP-R1DY (OEM product of ASHTECH Z-XII3) Antenna: ASHTECH 700718 (1998), ASHTECH 700578 (1999)

Sampling interval: $30 \mathrm{sec}$

Cutoff elevation angle: $15^{\circ}$

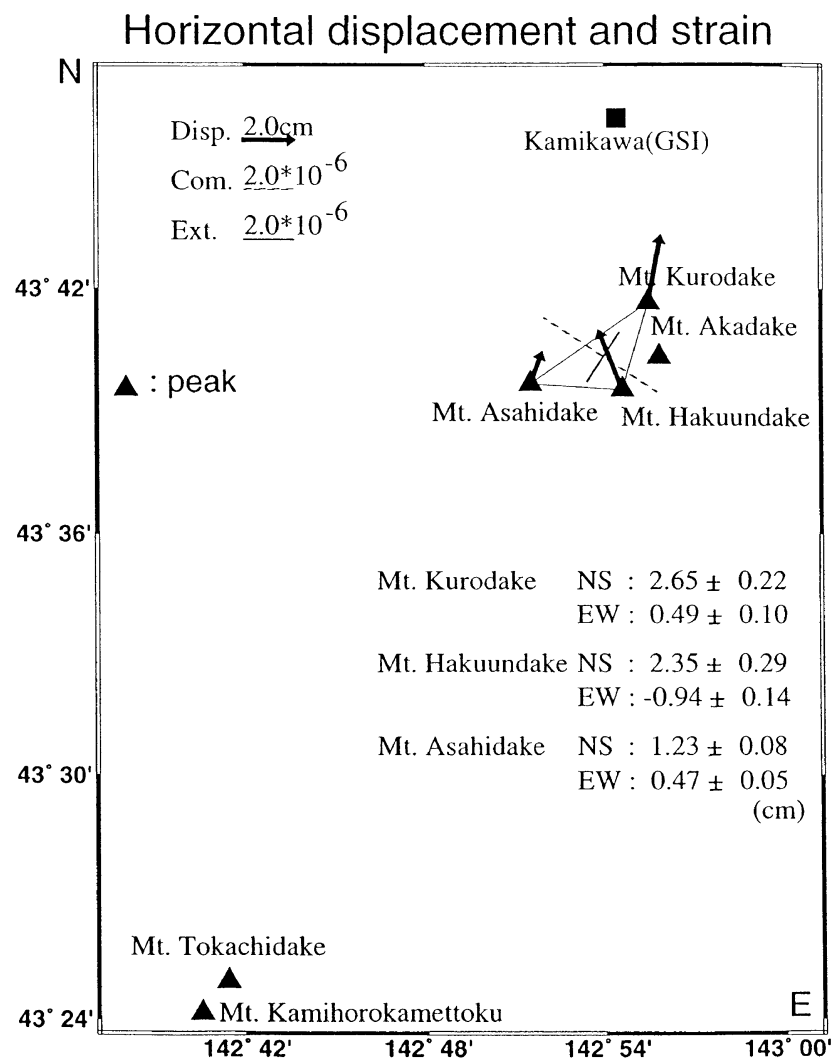

Fig. 3. Horizontal displacements estimated from the 1998 and 1999 GPS survey. They are calculated with respect to Kamikawa (GSI) station and indicated by arrows. Principal horizontal-strains from the displacements are also shown by solid and broken lines, respectively. Kamikawa GPS station of Geographical Survey Institute of Japan is plotted by a square, where we have used as the reference site. 


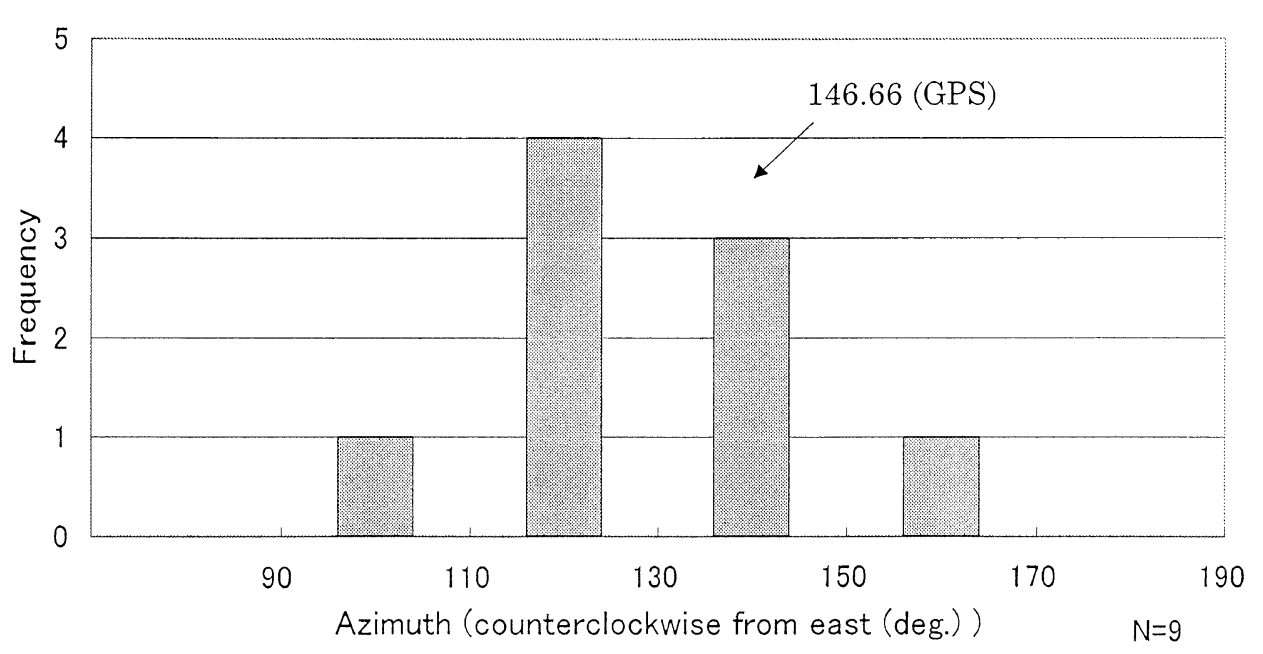

Fig. 4. Histogram of directions of maximum compressional axis of focal mechanism solutions of local earthquakes in the central part of Hokkaido (surrounding region of the Taisetsu) (Moriya, 1999). Direction is measured as azimuth angle counter-clockwise from East. Our estimate of $146.66^{\circ}$ by GPS analysis is also plotted.

tude of EW displacements at each observation, there may be a rank down in evaluating the displacement in this direction. However, the directions of displacements at Mt. Asahidake and Mt. Hakuundake are opposite. Strain field evaluated from this displacement field will be discussed in the following. General feature that we understand is the dominant NW-SE compression in the Taisetsu mountains.

Moriya (1999) studied the focal mechanism of local earthquakes in and around Hokkaido, Japan. Since the earthquakes are small with magnitude less than about 5, the mechanism solutions are obtained from $P$-wave initial motions of local observations. There are few earthquakes in our survey area. Some earthquakes in the surrounding region show the compressional axis dominantly in the direction between $\mathrm{N} 30^{\circ} \mathrm{W}$ and $\mathrm{N} 60^{\circ} \mathrm{W}$ as shown in Fig. 4. This is consistent with the general trend of the direction of our compressional axis (Fig. 4).

The phase-center offset among different antennas causes the uncertainty of vertical and horizontal components of site coordinates. In fact, there are about $1 \mathrm{~cm}$ vertical and about $1 \mathrm{~mm}$ horizontal offsets of antenna phase-centers between ASHTECH 700718 and ASHTECH 700578 which we have used. These would have been properly corrected by Bernese software. Variations of water vapor content and temperature at summit peaks would not generally influence the precision of horizontal component compared with vertical component of coordinates. This would justify our limited concern on the horizontal displacements at the summit peaks.

Triangulation survey in Japan by GSI has been summarized and the strain evaluated by the survey shows a compressional field in the mountain chain (GSI, 1987). The general trend lays in the direction from $\mathrm{N} 40^{\circ} \mathrm{W}$ to $\mathrm{N} 60^{\circ} \mathrm{W}$. Considering the absolute values of compressional strain, our estimates are twice or three times larger than those by the triangulation survey. There would be many possible reasons; for example 1) the deformation of the mountain peaks is larger than those in the surrounding mountain foot, 2) the annual to severalyear temporal variation of the deformation is larger than the triangulation result averaged for ten-year period, and 3) some occasional error is contained in our GPS measurement. This will be checked through the future survey.

A country-wide GPS network has been established by GSI in Japan. Crustal deformation near the Taisetsu mountain chain has been estimated from GPS data retrived by the network in the last few years (GSI, 1999) to reveal the general characteristic of the crustal deformation in Hokkaido. The number of observation stations in the Taisetsu mountains, however, is very sparse, and the amount of deformation is very small changing direction from place to place. Our result describes the local deformation field in the Taisetsu mountains to supplement the gap of the observation.

Acknowledgments. We acknowledge Geographical Survey Institute of Japan forwarding their GPS data for the present analysis. Prof. M. Kasahara, Hokkaido University, kindly facilitated GPS instruments for the field survey. We also thank graduate and undergraduate students of Hokkaido University who assisted us in the field.

\section{References}

Geographical Survey Institute, Horizontal Strain 1985-1883, Geographical Survey Institute Technical Report F1 No. 6, 1-133, 1987.

Geographical Survey Institute, http://mekira.gsi-mc.go.jp/ ENGLISH/index.html, 1999.

Hokkaido University, http://hkdpub.eos.hokudai.ac.jp/ javaseis/jmap/index.rcep.html, 1999.

Monthly Report on Earthquakes and Volcanoes in Japan, Japan Meteorological Agency, 20-21, January, 2000.

Moriya, T., Stress field in the crust inferred from earthquake mechanism solutions observed in and around Hokkaido, Japan, Earth Monthly, 21, 557-564, 1999 (in Japanese).

Rothacher, M. and L. Mervert, Bernese GPS Software Version 4.0, Astronomical Institute, University of Bern, 1-418, 1996.

Tada, T. and G. Kimura, Collision tectonics and crustal deformation at the southwestern margin of the Kuril Arc, Zisin II, 40, 197-204, 1987 (in Japanese).

T. Kaneso (e-mail: kaneso@MANDE001.sci.hokudai.ac.jp), J. Koyama, T. Moriya, and H. Takahashi 